\title{
CNS-Wide over Expression of Fractalkine Improves Cognitive Functioning in a Tauopathy Model
}

\author{
Dylan J. Finneran $^{1} \cdot$ Dave Morgan $^{2} \cdot$ Marcia N. Gordon ${ }^{2} \cdot$ Kevin R. Nash ${ }^{1}$
}

Received: 3 October 2018 / Accepted: 6 November 2018 / Published online: 29 November 2018

(C) The Author(s) 2018

\begin{abstract}
Accumulating evidence increasingly implicates regulation of neuroinflammation as a potential therapeutic target in Alzheimer's disease and other neurodegenerative disorders. Fractalkine (FKN) is a unique chemokine that is expressed and secreted by neurons and reduces expression of pro-inflammatory genes. To further demonstrate the utility of agents that increase FKN signaling throughout the central nervous system as possible therapies for AD, we assessed the impact of soluble FKN (sFKN) over expression on cognition in tau depositing rTg450 mice after the onset of cognitive deficits. Using adeno-associated virus serotype 4, we infected cells lining the ventricular system with soluble FKN to increase FKN signaling over a larger fraction of the brain than achieved with intraparenchymal injections. We found that soluble FKN over expression by cells lining the ventricles significantly improved cognitive performance on the novel mouse recognition and radial arm water maze tasks. These benefits were achieved without detectable reductions in tau hyperphosphorylation, hippocampal atrophy, or microglial CD45 expression. Utilizing qPCR, we report a significant increase in Vegfa expression, indicating an increase in trophic support and possible neovascularization in AAV-sFKN-injected mice. To our knowledge, this is the first demonstration that FKN over expression can rescue cognitive function in a tau depositing mouse line.
\end{abstract}

Keywords Alzheimer's disease $\cdot$ Tauopathy $\cdot$ Fractalkine $\cdot$ CX3CL1 $\cdot$ Microglia

\section{Introduction}

Fractalkine (CX3CL1; FKN) is unique among chemokines because it is the only member of the $\mathrm{CX} 3 \mathrm{C}$ motif family and has a one-to-one relationship with its receptor, CX3CR1 (Bazan et al. 1997; Imai et al. 1997; Pan et al. 1997). Produced as a transmembrane protein, FKN can undergo proteolytic cleavage by a disintegrin and metalloprotease (ADAM) 10/17 or cathepsin S to produce a secreted, soluble form of the protein (sFKN) (Garton et al. 2001; Hundhausen et al. 2003; Jones et al. 2013). There is evidence that the membrane-associated (full-length) and ectodomain (soluble) forms of FKN may have different functional roles and activate

Kevin R. Nash

knash@health.usf.edu

1 Department of Molecular Pharmacology \& Physiology, Morsani College of Medicine, University of South Florida, Byrd Alzheimer's Institute, $4001 \mathrm{E}$ Fletcher Ave, Tampa, FL 33617, USA

2 Translational Science and Molecular Medicine, Michigan State University, GRRC, 400 Monroe Ave. NW, Grand Rapids, MI 49503, USA the receptor differently (Clark and Malcangio 2012; Kim et al. 2011). In the periphery, the full-length form is important for monocyte adhesion to endothelial cells while the soluble form may act as a chemoattractant for lymphocytes and monocytes (Imai et al. 1997). In the central nervous system (CNS), FKN is produced by neurons and its receptor is expressed only on microglia (Cardona et al. 2006; Harrison et al. 1998). FKN signaling in the CNS blunts microglial activation, reducing production of pro-inflammatory cytokines such as interleukin (IL)-1 $\beta$, IL-6 and tumor necrosis factor- $\alpha$ (Lyons et al. 2009).

Fractalkine's role in neurodegenerative diseases has been of considerable interest in the last few years. Initial work disrupting FKN signaling in animal models (receptor or ligand knockouts) demonstrated increased Parkinson's disease pathology, tauopathy, and amyotrophic lateral sclerosis (Bhaskar et al. 2010; Cardona et al. 2006), suggesting that dysregulation of microglial activation can result in worsening of disease pathology and neurodegeneration. However, disrupting FKN signaling in amyloid-depositing mice showed amelioration of the pathology due to increased microglial phagocytosis of the extracellular amyloid plaques (Lee et al. 2010b). Conversely, studies investigating the over expression of 
FKN showed opposite results to disruptions in signaling, generally leading to favorable improvements in disease pathology. The soluble form of FKN was shown to be beneficial in multiple models of Parkinson's disease (Morganti et al. 2012; Nash et al. 2015; Pabon et al. 2011). In Alzheimer's disease, we reported that adenoassociated virus (AAV) over expression of sFKN in the hippocampus of the rTg4510 mouse model of tauopathy resulted in reduced tau pathology, amelioration of neuron loss, and reduction of microgliosis. However, there was no improvement in cognitive performance after sFKN over expression, which may be attributed to the limited distribution of the treatment which was targeted to the dentate gyrus of the hippocampus (Nash et al. 2013).

Here, we further investigate the therapeutic ability of sFKN by addressing two questions: does a more global distribution of CNS sFKN expression have a greater cognitive impact and can increased sFKN expression have an impact in animals that already have advanced tau pathology? The latter would be more clinically informative because most AD patients would have significant tau pathology at the time of their diagnosis. To achieve this, we used a novel delivery method into five-month old rTg4510 animals, which present with insoluble tau and cognitive deficits (Dickey et al. 2009; Santacruz et al. 2005). We utilized the unique capability of AAV serotype 4 to infect cells lining the ventricular system, combined with the soluble nature of our therapeutic gene product, to distribute $\mathrm{SFKN}$ to the CNS via secretion into the CSF. This has been achieved with other secreted proteins (Davidson et al. 2000b; Liu et al. 2005; Tenenbaum et al. 2004). We demonstrate here that elevated sFKN expression via AAV4, during late stage disease pathology, can partially rescue behavioral deficits but does not appear to alter disease progression.

\section{Methods}

\section{Adeno-Associated Virus Production}

The ectodomain (amino acids 1-336 containing the chemokine domain and mucin-like stalk) of mouse fractalkine was isolated from mouse cDNA and cloned into pTR2-MCS vector at the Age I and Nhe I sites as described previously (Morganti et al. 2012; Nash et al. 2013). This vector contained the AAV2 terminal repeats and hybrid cytomegalovirus-chicken $\beta$-actin (CBA) promoter. A C-terminal hemagglutinin (HA)-tag was added for protein detection. rAAV4 particles were generated as described previously (Carty et al. 2010) and quantified using a dot-blot method with a non-radioactive biotinylated probe for fractalkine generated by polymerase chain reaction (Burger and Nash 2016; Nash et al. 2013).

\section{Transgenic Mice and Breeding}

Animal experiments were conducted in accordance with the National Institute of Health Guide and Use of Laboratory Animals and were approved by the Institutional Animal Care and Use committee of the University of South Florida. Parental mutant tau and tetracycline-controlled transactivator protein strains were maintained separately and bred to produce rTg4510s and littermate nontransgenic (NonTg) and tetracycline-controlled transactivator protein (tTA) mice as previously described (Santacruz et al. 2005). Littermate tTA and NonTg mice were used as behavioral controls, as we observed modest differences in performance between tTA and NonTg mice. Study animals were given food and water ad libitum and maintained on a 12-h light/dark cycle.

\section{Surgical Procedure and Tissue Collection}

Immediately before surgery, mice were weighed and anesthetized with isoflurane. Surgeries were performed using a stereotaxic apparatus using convection enhanced delivery as described previously (Burger and Nash 2016; Carty et al. 2010; Nash and Gordon 2016). Animals receiving AAV4 sFKN $\left(3.4 \times 10^{12} \mathrm{vg} / \mathrm{mL}\right)$ were injected bilaterally into the lateral ventricles with $5 \mu \mathrm{L}$ of virus in sterile PBS per site (coordinates from bregma: $-0.4 \mathrm{~mm}$ anteroposterior, $\pm 1.0 \mathrm{~mm}$ lateral, \& $-2.4 \mathrm{~mm}$ vertical). Control animals received AAV9 UF11 $\left(5 \times 10^{12} \mathrm{vg} / \mathrm{mL}\right)$ expressing green fluorescent protein (GFP) were injected as described previously (Carty et al. 2010).

Three months post-surgery, mice were weighed and overdosed with pentobarbital $(200 \mathrm{mg} / \mathrm{kg})$. CSF was collected as described (Liu and Duff 2008) and mice were perfused with $25 \mathrm{~mL}$ of $0.9 \%$ normal saline. Brains were collected immediately after perfusion. The right hemisphere was dissected and frozen on dry ice for biochemical analysis. The left hemisphere was immersion fixed in $4 \%$ paraformaldehyde for $24 \mathrm{~h}$. The fixed hemisphere was cryoprotected with successive incubations in 10\%, 20\%, and 30\% sucrose solutions for $24 \mathrm{~h}$ in each solution. Brains were frozen on a cold stage and sectioned horizontally ( $25 \mu \mathrm{m}$ thick) on a sliding microtome and sections were stored in PBS with $10 \mathrm{mM}$ sodium azide at $4{ }^{\circ} \mathrm{C}$. For rTg4510 mice, every twelfth section was $50 \mu \mathrm{m}$.

\section{Tissue Homogenization, ELISA, and Western Blotting}

Anterior cortex and hippocampal samples were homogenized in TBS with protease inhibitor cocktail (Sigma Aldrich, St. Louis, MO, USA; Cat. No. P8340), phosphatase inhibitor cocktails II and III (Sigma Aldrich, St. Louis, MO, USA; Cat. Nos. P5726 \& P0044, respectively), and Benzonase (Sigma Aldrich, St. Louis, MO, USA; $25 \mathrm{U} / \mathrm{mL}$ final concentration) at $10 \mathrm{vol} / \mathrm{wt}$ of tissue. Tissue was homogenized with a rotating pestle and briefly sonicated $(3 \times 3 \mathrm{~s})$. The samples 
were centrifuged for $10 \mathrm{~min}$ at $10,000 \mathrm{x} g$ at $4{ }^{\circ} \mathrm{C}$. An aliquot $(15 \mu \mathrm{L})$ of the resulting supernatant was taken for FKN ELISA. The pellet was resuspended in the remaining supernatant and detergents added to a final concentration of $0.01 \%$ SDS, $0.1 \%$ NP40, and $0.05 \%$ sodium deoxycholate. Samples were then centrifuged at $40,000 \times g$ for $30 \mathrm{~min}$ at $4{ }^{\circ} \mathrm{C}$. The resulting pellet was resuspended in $70 \%$ formic acid $(2 \mu \mathrm{L} / \mathrm{mg}$ tissue) and incubated for $60 \mathrm{~min}$ at room temperature. An equal volume of $1 \mathrm{M}$ Tris $\mathrm{pH} 7.5$ was added and the sample was neutralized to $\mathrm{pH} 7.5$ with $\mathrm{NaOH}$ if needed. The soluble fraction was taken for Western blotting and total protein concentration was determined by Pierce BCA protein assay (ThermoFisher Scientific, Walthman, MA, USA). For Western blotting, $1 \mu \mathrm{g}$ of protein was loaded for each sample. H150 (total tau; Sigma), anti-phospho-Ser199/202 tau (pSer199/202, Anaspec, Fremont, CA, USA), and antiphosphoSer396 tau (pSer396, Anaspec, Fremont, CA, USA) were used to assess tau pathology. All signals were normalized to $\beta$-actin (ThermoFisher Scientific, Walthman, MA, USA). For the insoluble fraction, which does not contain actin, an equal volume of each sample was loaded. A fractalkine ELISA was obtained from R\&D Systems and the manufacturer's protocol was followed.

\section{Behavioral Assessment}

All behavioral tasks were conducted by an observer blinded to treatment condition and genotype of the mice. The open field was used as a general measure of activity and anxiety. Animals were recorded for $15 \mathrm{~min}$ in a $40 \mathrm{~cm}$ by $40 \mathrm{~cm}$ open field box with video tracking software (ANY-Maze, Stoelting, Wood Dale, IL, USA). General activity levels were evaluated by distance traveled in the open field.

Each animal was placed for a single, 5-min trial in a Ymaze and activity was recorded (ANY-Maze, Stoelting, Wood Dale, IL, USA). The number of arm entries and spontaneous alternation, entering each arm in sequence without repetition, was expressed as a percentage as previously described (Brownlow et al. 2014).

Short term memory was evaluated by the novel object recognition task. Two objects, similar in scale to the mice, were placed in the $40 \mathrm{~cm} \times 40 \mathrm{~cm}$ open field arena approximately 3-5 cm from the outer wall. Each animal was given three 5min familiarization trials with a 5-min inter-trial interval. On the fourth trial, one of the objects was switched for a novel object. Animals were given five minutes to explore the objects and their activity was recorded (ANY-Maze, Stoelting, Wood Dale, IL, USA). The objects and arena were cleaned between trials with $10 \%$ ethanol to minimize olfactory cues. Working memory was evaluated by measuring the time spent with familiar object and novel object on the final trial.

To overcome the disinterest the mice showed in the objects, the mice were also tested in a variant of the NOR task using unfamiliar mice as the stimuli as previously described (Brownlow et al. 2014). Briefly, the test mouse was given one 5-min habituation trial to its environment. It was then introduced to two sex-matched bait mice, located in the left or right chamber of the three-chambered arena. The test mouse had two five-minute trials with a five-minute inter-trial interval to familiarize itself with the bait mouse. On the fourth trial, one of the bait mice was switched for a novel bait mouse. The test mouse was given another five minutes to explore the arena and its activity was recorded (ANY-Maze, Stoelting, Wood Dale, IL, USA). Preference for the novel mouse was assessed by measuring time spent in the chamber of the arena containing the novel mouse.

Radial arm water maze (RAWM) has been described in detail, including sample score sheets, previously (Alamed et al. 2006). The radial arm water maze contained six arms radiating from an open central area with a hidden escape platform located at the end of one of the arms. Around the pool, several extra-maze cues were hung to allow for spatial navigation. On each trial, the mouse was allowed $60 \mathrm{~s}$ to find the platform. The platform was located in the same goal arm on each trial. On day one, the mice were given 15 trials alternating between a visible and hidden platform. On day two, mice were given 15 additional trials, all with a hidden platform. The start arm was varied for each trial, forcing mice to rely on the extra-maze spatial cues to find the platform instead of procedural memory. The goal arm for each mouse was different to avoid odor cues revealing the platform location. Entry into an incorrect arm (all four limbs in the arm) was counted as an error. Failure to enter an arm for $15 \mathrm{~s}$ was also counted as an error. The errors of blocks of three trials were averaged for data analysis. Mice that made one or fewer errors on the last block of Day 2 were considered to have learned the platform location.

On the third day, a reversal trial was performed with the goal arm moved $180^{\circ}$ across the pool. The mice were again given 15 trials, all with the hidden platform, to learn its new location. On the fourth day, the arm insert was removed from the pool, the extra-maze cues were taken down, and the platform was raised above the surface of the water with a flag attached to confirm that all mice were able to see and capable of ascending the platform. Latency to find and ascend the platform was recorded with a maximum swim time of 60s.

To assess thermal hyperalgesia, mice were placed on a hot plate at $50{ }^{\circ} \mathrm{C}$. Latency to hind paw withdrawal was measured (Woolfe and Macdonald 1944).

\section{Immunohistochemistry}

Six to eight sections approximately $200 \mu \mathrm{m}$ apart spanning the hippocampus were chosen for analysis. Immunohistochemical experiments were performed as described previously (Gordon et al. 2002). Briefly, sections for each animal were placed into a 
multisample staining tray. Endogenous peroxidases were blocked (10\% methanol, 3\% hydrogen peroxide in PBS for $15 \mathrm{~min})$ and tissue was permeabilized $(0.2 \%$ lysine, $0.1 \%$ Triton X-100 in PBS for $30 \mathrm{~min}$ ). Sections were incubated overnight in appropriate primary antibody: anti-pSer396 (Anaspec, Fremont, CA, USA); anti-CD45 (ThermoFisher Scientific, Walthman, MA, USA); anti-IBA-1 (Wako, Richmond, VA, USA); or HRP-conjugated anti-HA (Roche, Indianapolis, IN, USA). Sections were washed three times in PBS, then incubated for two hours with corresponding biotinylated secondary antibody (Vector Laboratories, Burlingame, CA, USA), if necessary. The tissue was again washed and incubated with Vectastain Elite ABC Kit (Vector Laboratories) for enzyme conjugation. Finally, sections were stained using $0.05 \%$ diaminobenzidine and $0.03 \%$ hydrogen peroxide for five minutes. Each immunohistochemical assay omitted some sections from primary antibody incubation to evaluate nonspecific binding of the secondary. Sections were mounted onto slides, dehydrated, and coverslipped.

Gallyas staining was performed as previously described (Lee et al. 2010a). Staining was performed on pre-mounted tissue sections that had been dried for a minimum of $24 \mathrm{~h}$. Prior to staining sections were rehydrated for $30 \mathrm{~s}$. Slides were treated with 5\% periodic acid for five minutes, washed with water, and incubated sequentially in silver iodide $(1 \mathrm{~min})$ and $0.5 \%$ acetic acid (10 $\mathrm{min}$ ) prior to being placed in developer solution $(2.5 \%$ sodium carbonate, $0.1 \%$ ammonium nitrate, $0.1 \%$ silver nitrate, $1 \%$ tungstosilicic acid, $0.7 \%$ formaldehyde). Slides were incubated in developer solution until color developed after which they were placed in $0.5 \%$ acetic acid to stop the reaction $(3 \mathrm{~min})$. Slides were incubated in $0.1 \%$ gold chloride solution ( $5 \mathrm{~min}$ ), washed with water, and incubated in $1 \%$ sodium thiosulphate solution $(5 \mathrm{~min})$. After a final wash, slides were dehydrated and coverslipped.

Stained sections were imaged using a Zeiss Axioscan.Z1 scanning microscope and Neurocyte IAE software (created by Andrew Lesniak) was used for analysis. The area of positive staining in the hippocampus was analyzed. The software used hue, saturation, and intensity to segment the images and these values were held constant for analysis of every section of every animal in each stain. These values were established on sections of high and low levels of staining to identify positive staining over background (Gordon et al. 2002).

\section{RNA Isolation and Real-Time PCR}

RNA was isolated from posterior cortex using the Zymo Quick-RNA Miniprep Plus kit (Zymo Research, Irvine, CA, USA; cat. no. R1057) per the manufacturer's recommended protocol. EXPRESS One-Step Superscript qRT-PCR Kit (cat. no. 11718200) and TaqMan Gene Expression Assays were purchased from ThermoFisher (Walthman, MA, USA). Primers for the target genes Tnf (Mm00443256_m1), Il1b
(Mm00434228 m1), Il6 (Mm00446190_m1), Il12a (Mm00434169_m1), I110 (Mm01288386_m1), Vegfa (Mm00437306 m1), Il4 (Mm00445259 m1), Marco (Mm00440265_m1), Itgam (Mm00434455_m1), CD68 (Mm03047343_m1), Arg1 (Mm00475988_m1), Nos2 (Mm00440502_m1), C1qa (Mm00432142_m1), Itgax (Mm00498701_m1), and the housekeeping gene Pgk1 (Mm00435617_m1) were used per the manufacturer's recommended protocol. Fifty nanograms of RNA were loaded per well and data collected in a Bio-Rad CFX96 thermal cycler $\left(50{ }^{\circ} \mathrm{C}\right.$ for $15 \mathrm{~min}, 95^{\circ} \mathrm{C}$ for $2 \mathrm{~min}, 40$ cycles of: $95^{\circ} \mathrm{C}$ for $15 \mathrm{~s}, 60^{\circ} \mathrm{C}$ for $\left.1 \mathrm{~min}\right)$. Data was analyzed using the $\Delta \Delta \mathrm{C}_{\mathrm{T}}$ method (Schmittgen and Livak 2008).

\section{Statistical Analysis}

Statistical analysis was performed using SPSS Statistics (IBM, Armonk, NY, USA). For behavioral tasks, all groups were assessed using a one-way analysis of variance (ANOVA) was performed with Fisher's LSD post-hoc analysis. For the novel object recognition task, a two-tailed Student's t test was used to compare time spent with the familiar object to time spent with the novel object on trial four. The novel mouse recognition task was analyzed with a two-way ANOVA and Fisher's LSD with Group and Chamber as fixed factors. For tau western blotting and immunostaining, where there was no signal from mice lacking P301L tau expression, a two-tailed Student's $t$ test was utilized to compare $\mathrm{sFKN}$-treated mice to GFP-injected controls. Immunostaining for CD45 and IBA-1 was analyzed with a one-way ANOVA and Fisher's LSD posthoc analysis comparing all groups. The threshold for significance was set at $p=0.05$.

\section{Results}

\section{Intraventricular Injection of AAV4 Increased Soluble FKN}

Adeno-associated virus serotype 4 has been reported to readily infect cells lining the ventricular system in the CNS (Davidson et al. 2000b; Dodge et al. 2010; Liu et al. 2005; Tenenbaum et al. 2004). Here, we sought to take advantage of this AAV4 tropism to infect cells lining the ventricular system in order to increase the distribution of soluble fractalkine $(\mathrm{sFKN})$ agonism throughout the CNS with minimal intracranial injections. Fig. 1a describes the timing of the FKN administration relative to assessment of behavioral, histological and biochemical endpoints. To confirm increased sFKN levels in the parenchyma, we performed an ELISA on soluble fractions of brain homogenate three months post-injection. Injection with AAV4 sFKN increased SFKN concentrations in the hippocampus but not the anterior cortex (Fig. 1b) compared with to control-injected 
Fig. 1 AAV4 over expressing sFKN transduced cells of the lateral ventricle leading to increased $\mathrm{SFKN}$ in the hippocampus. a Study design. Five-month old rTg4510s were injected with AAV4-sFKN (3.4 ×

$10^{12} \mathrm{vg} / \mathrm{mL}$ ) and survived for two months prior to behavioral assessment. Tissue was collected at eight months of age. b A FKN ELISA showed increased sFKN in the hippocampus of animals injected with AAV4-sFKN compared to GFP-injected rTg4510 and uninjected tTA control mice $(n=9-12)$. c AntiHA Western blot showed sFKN secretion into the CSF of AAV4sFKN injected mice. $\mathbf{d}$

Representative images of sections stained for anti-HA showed positive staining in the ventricles of animals that received AAV4sFKN, but not in control mice (scale bar $=250 \mu \mathrm{m})$. Data represented as mean \pm SEM. * denotes $p<0.05$ by Fisher's LSD a

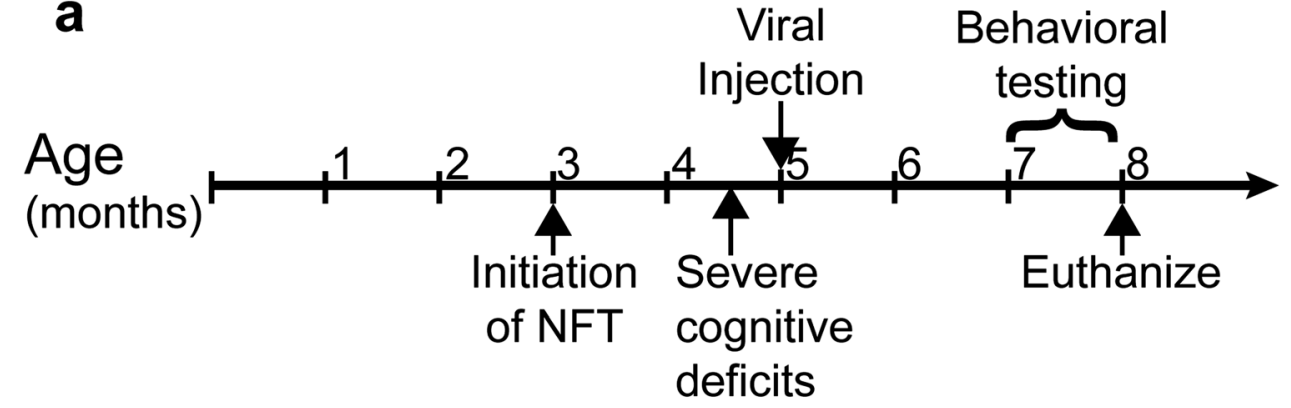

b
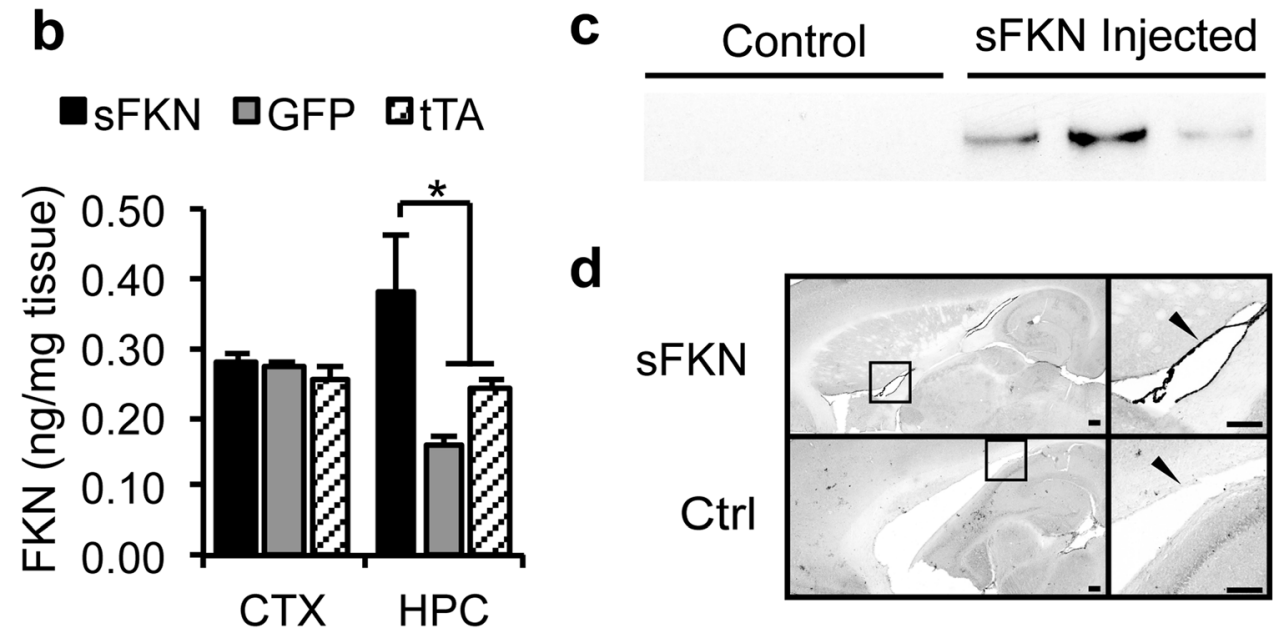

d

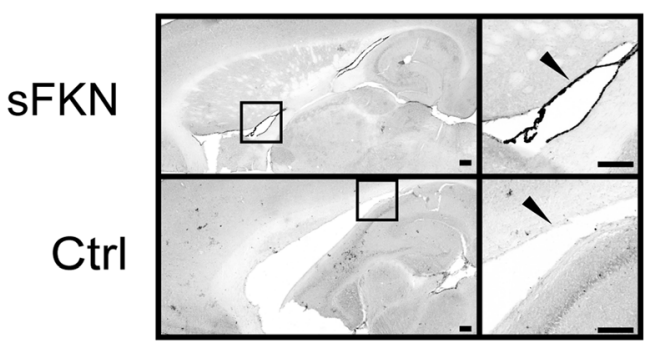

rTg4510s. Staining for anti-HA shows positive staining in the lining of the ventricles in injected animals not present in uninjected control mice (Fig. 1d). We also observed recombinant sFKN expression in the CSF by Western analysis for HA present on the sFKN construct (Fig. 1c). Thus, AAV4 overexpressing sFKN delivered into the ventricles causes secretion of sFKN into the CSF, which diffuses into the hippocampus leading to supraphysiological levels of FKN.

\section{Increased Soluble FKN Expression Ameliorated Hyperactivity and Improved Cognition}

rTg4510 mice have been shown previously to be hyperactive (Brownlow et al. 2013, 2014; Joly-Amado et al. 2016). We also observed increased locomotion in transgenic mice treated with control AAV injections compared with either tTA or nontransgenic uninjected mice (Fig. 2a, b). Increased soluble fractalkine signaling ameliorated this behavior with sFKNtreated mice both traveling a shorter distance in the open field (Fig. 2a) and entering fewer arms in the Y-maze (Fig. 2b) than GFP-injected control mice. We observed no significant differences between groups in spontaneous alternation in the Ymaze (data not shown). While sFKN over expression did not improve object recognition (Fig. 1c), it did significantly improve novel mouse recognition. Mice treated with sFKN spent more time interacting with the novel mouse than the familiar mouse while GFP-injected transgenic mice showed no preference for either the novel, familiar, or empty center chamber of the apparatus (Fig. 2d).

Previous reports have implicated a truncated soluble variant of FKN generated by Cathepsin S cleavage in neuropathic pain (Clark and Malcangio 2012; Clark et al. 2007, 2009). To investigate if the entire ADAM 10/17 cleaved ectodomain of FKN may contribute to this, we assessed thermal hyperalgesia on a hot plate. Animals over expressing the entire ectodomain of FKN did not have a change in the latency to hind paw withdrawal (Fig. 3), indicating that they did not have a change in pain threshold. Nor did they exhibit any signs of adverse sickness behavior, such as hunching. Thus, we conclude the mice were not made hyperalgesic by the sFKN expression.

We have previously reported $\mathrm{rTg} 4510$ mice display a deficit in spatial learning and memory by five months of age. Using the radial arm water maze task, we observed that AAV-GFP-treated control transgenic mice displayed a larger number of errors per block compared with either tTA or nontransgenic mice (Fig. 4a), commit significantly more total errors on both day 1 and day 2 (Fig. 4b), and never attain criterion performance of $<1$ error per block by the end of day 2. In contrast, treatment with $\mathrm{SFKN}$ revealed a partial rescue in performance, with a smaller number of average errors on Block 10 and a significant reduction in errors made on Day 2 of testing compared to GFP-injected controls (Fig. 4a, b). However, sFKN over expression was not able to improve performance in the reversal portion of the task (Fig. 4c, d). 
Fig. 2 AAV4 sFKN over expression reduced hyperactivity and improved novel mouse recognition. a Distance travelled in open field was reduced in sFKN animals; $\mathbf{b}$ arm entries Ymaze were reduced in $\mathrm{SFKN}$ animals. Locomotor activity of tTA (hatched bars) and NonTg (open bars) mice was lower than locomotor activity in AAV-GFPinjected transgenic mice in both tests. c Nontransgenic mice showed a preference (increased interaction time) for the novel object over the familiar object in the novel object recognition test, but the other test groups did not show a preference. $\mathbf{d}$ Nontransgenic, tTA and AAVsFKN-treated mice showed a significant preference for interacting with a novel mouse, but AAV-GFP-treated mice did not. Data represented as mean \pm SEM, $n=9-12 . *$ denotes $p<0.05$; *** denotes $p<0.001$ by Fisher's LSD
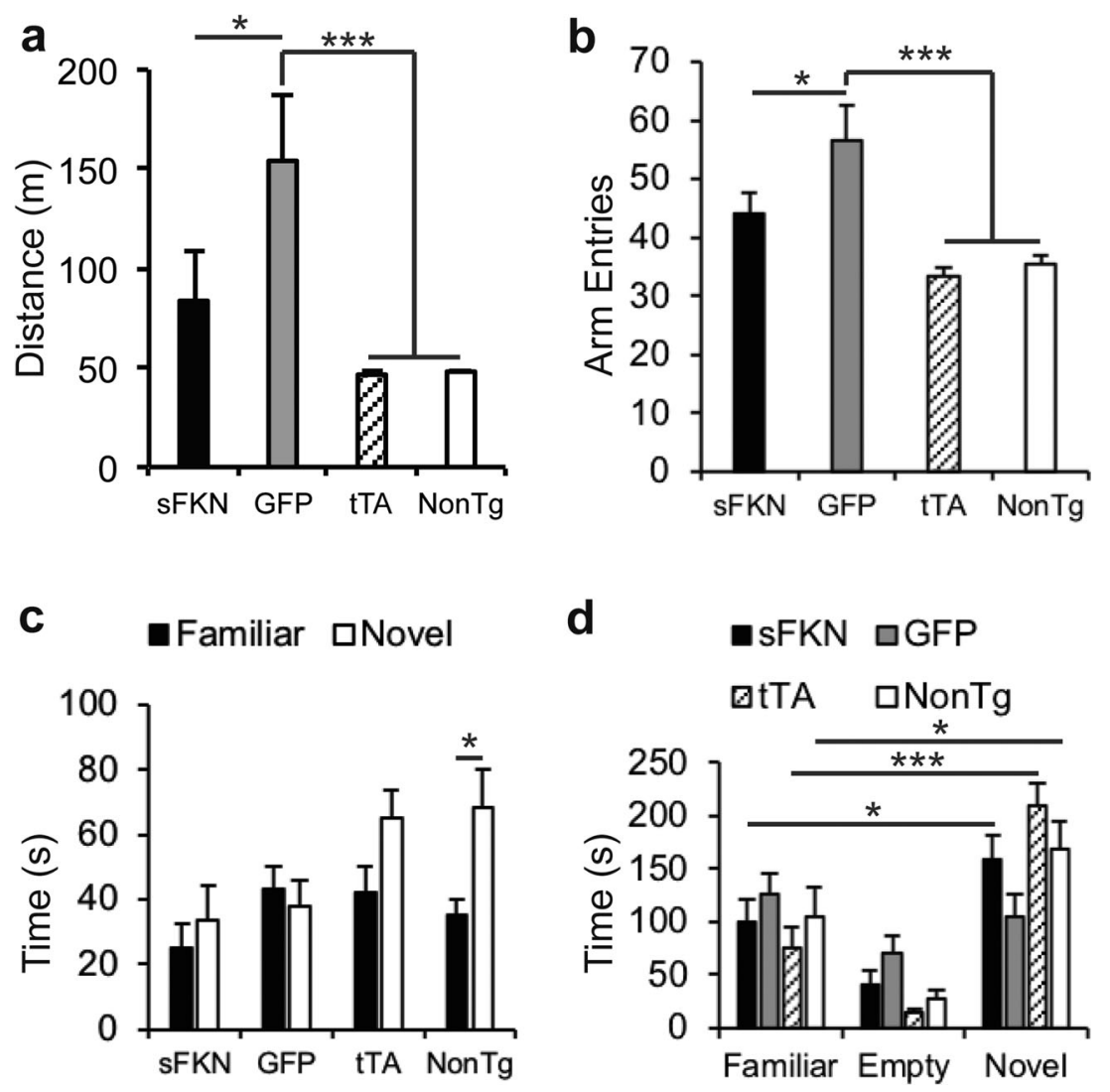

d

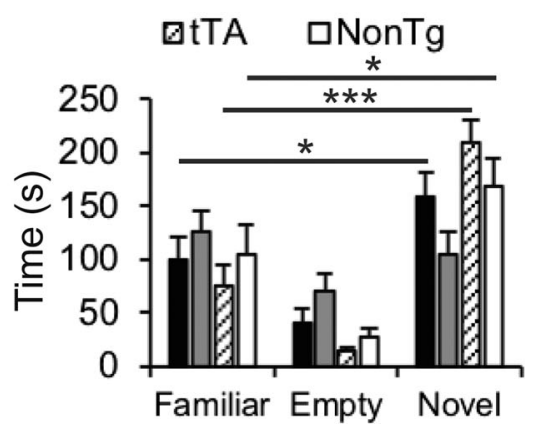

\section{Increased Soluble FKN Signaling Did Not Reduce Tauopathy}

We did not observe a significant reduction in either total (H150) or phospho-tau (pSer199/202 \& pSer396) in soluble

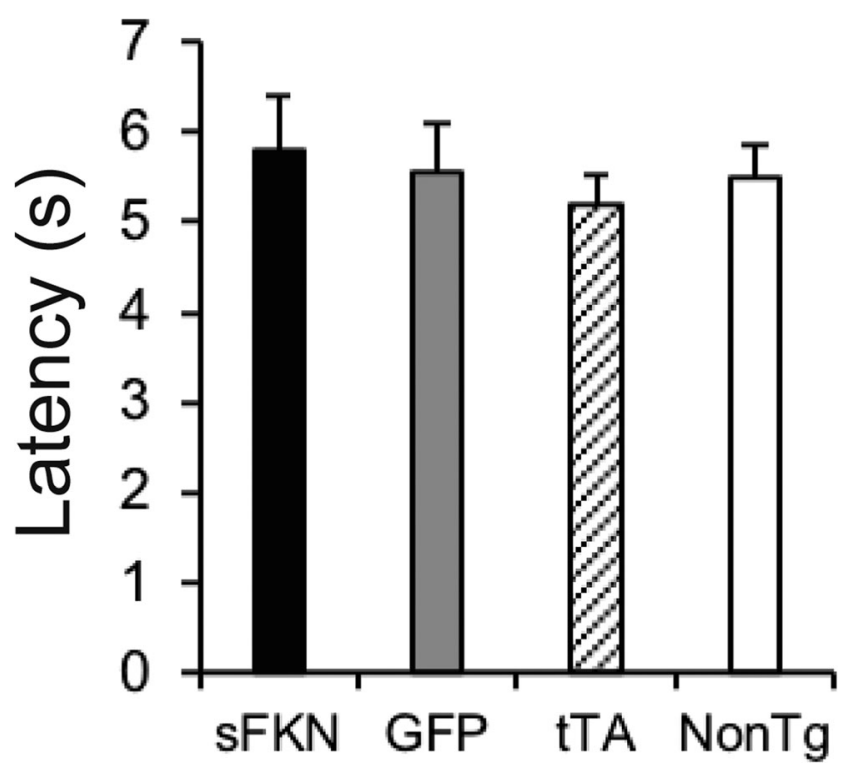

Fig. 3 Over expression of the ectodomain of FKN did not cause thermal hyperalgesia. Graph of latency to withdraw hind paw from hot plate. Over expression of the ectodomain of FKN (with mucin-like stalk), did not affect latency to respond to heat after. Data represented as mean \pm SEM, $n=9-12$ hippocampal homogenates (Fig. 5a, b) in animals treated with sFKN. Unexpectedly, we observed a significant increase in total insoluble tau with a trend for increased forms of phospho-tau (Fig. 5c, d). However, we did not observe significant increases in immunohistochemical staining of pSer396 (Fig. 6a, c) or in Gallyas staining, thought to represent tau tangles (Fig. 6a, b). Furthermore, we did not observe an amelioration of hippocampal atrophy in AAV-sFKN-injected rTg4510s compared to AAV-GFP-injected rTg4510s (Fig. 7). This is not unexpected given the mice would have already shown significant atrophy at time of viral injection.

\section{Increased Soluble FKN Signaling Did Not Reduce Microglial Markers}

We have previously shown that CD45, a marker of microglial activation, was elevated in rTg4510s and that parenchymal sFKN over expression reduced this marker (Nash et al. 2013). However, we did not observe a significant reduction in CD45 staining in animals over expressing sFKN in this experiment (Fig. 8a, b). Furthermore, we did not observe a reduction in IBA-1, a pan-marker for microglia in animals over expressing sFKN (Fig. 8c). When we examined expression of a panel of innate immunity-related genes using RNA from the posterior cortex, we did not observe changes in a number of microglial markers but Vegfa was significantly 
Fig. 4 sFKN over expression improved performance on RAWM but not on Reversal learning. a Graph of errors made during day 2 training in RAWM. Over expression of sFKN reduced average errors made on the last block of day 2; $\mathbf{b}$ Graph of total errors made on day 1 and day 2 of RAWM. sFKN reduced the total number of errors made on Day 2 compared to AAV-GFP injected rTg4510s. c Errors made during reversal testing. d Graph of total errors made during reversal testing. sFKN over expression did not reduce average errors per block compared GFP animals. Data represented as mean $\pm \mathrm{SEM}$, $n=9-12 . *$ denotes $p<0.05$; ** denotes $p<0.01$; *** denotes $p<0.001$ by Fisher's LSD a
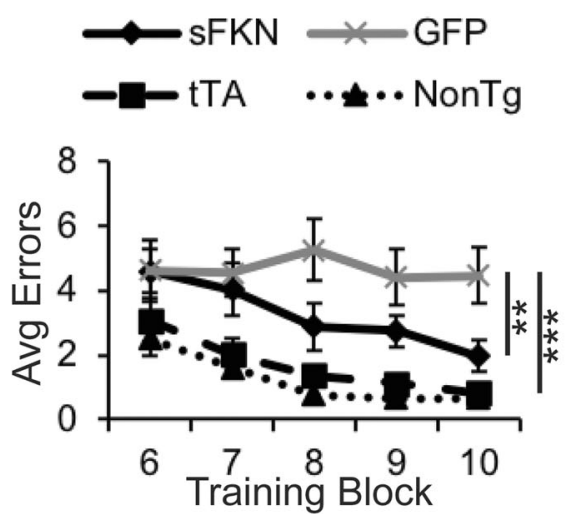

C
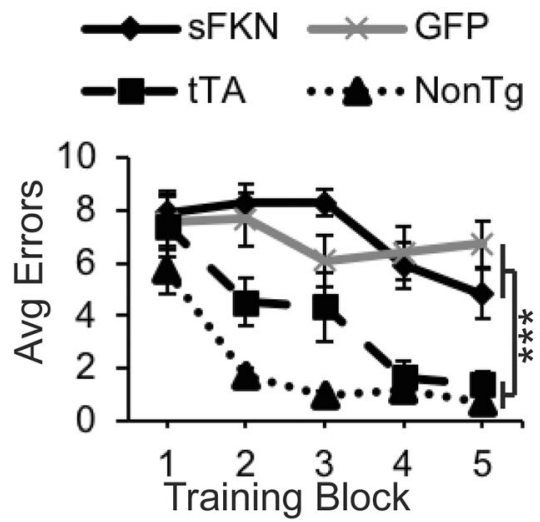

b

sFKN $\square$ GFP 口tTA 口NonTg

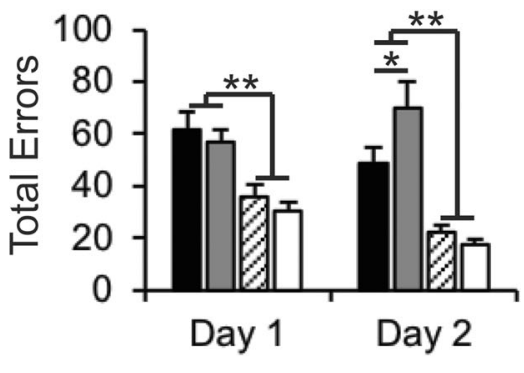

d

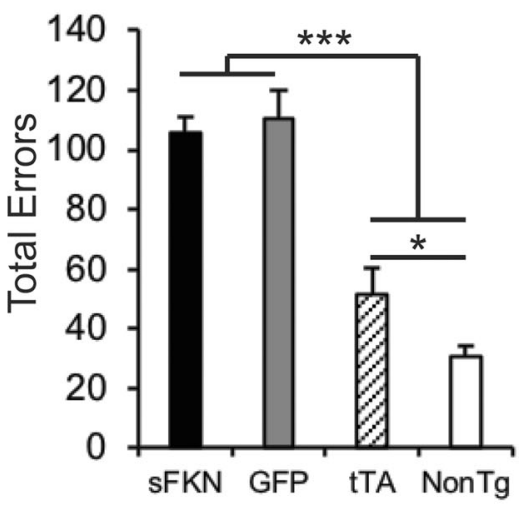

elevated in AAV-sFKN-injected rTg4510s compared to control injected rTg4510s (Fig. 9).

\section{Discussion}

Microglia play a key role in Alzheimer's disease pathogenesis. Previous studies showed that increasing microglial activation exacerbates tau pathology while reducing microglial activation can reduce tau pathology (Cho et al. 2011; Herber et al. 2007; Lee et al. 2010a, 2010b). We previously demonstrated that increasing soluble fractalkine agonism in the rTg4510 mouse model of tauopathy reduced pathology and neurodegeneration. However, the treatment was administered at a preventative timepoint, with administration of virus prior to significant tau pathology formation (injection at 3 months of age). In this study we wanted to examine if sFKN could have beneficial effects when administered at a more therapeutic timepoint, by administering virus after significant disease pathology and memory deficits had already been established (injection at 5 months of age). This would reflect a more clinically relevant setting where diagnosed patients would already exhibit significant tau deposition. The current study also differed from our previous work in that our delivery method in the previous study targeted only the hippocampus with injections directly into the parenchyma; here we sought to maximize treated brain regions while minimizing the number of injections required with the use of AAV4. We envisioned that intracerebroventricular (ICV) injections would reduce tissue damage to brain regions already burdened with pathology, neuron loss, and gliosis while maximizing distribution of the therapeutic gene product, another key consideration for translation to the clinic.

Previous studies showed the rAAV4 vector can efficiently infect cells of the lateral ventricle (Davidson et al. 2000a; Liu et al. 2005). More importantly, it has been reported that ICV and intrathecal delivery of AAV4 and AAV2 vectors encoding lysosomal enzymes, which were also secreted from transduced cells, has proven very effective in providing therapeutic levels of enzyme throughout the CNS in adult mouse models of lysosomal storage disease (Liu et al. 2005; Watson et al. 2006). ICV delivery of an AAV4 vector encoding hIFN- $\beta$ has also been shown to be an effective approach to curb glioblastoma tumor growth (Meijer et al. 2009). These data suggest that secretion of $\mathrm{sFKN}$ from a lateral ventricle injection may be sufficient to provide therapeutic levels of sFKN protein throughout the CNS. In this study, we show that AAV4 sFKN infected the cells lining the lateral ventricles and increased $\mathrm{sFKN}$ levels in the CSF and hippocampus of injected mice. We observed sFKN expression in cells throughout the ventricular system including the cerebral 
Fig. 5 sFKN did not ameliorate tauopathy and increased insoluble total tau. a Graph of tau and phospho-tau levels from Western blot analysis. Soluble total tau (H150) and phospho-tau (pS199/ 202 \& pS396) were unchanged by sFKN over expression. $\mathbf{b}$ Displays representative Western blots of monomeric tau at $55 \mathrm{kDa}$. c Graph of insoluble tau and phospho-tau levels from Western blot analysis. sFKN over expression increased insoluble total tau with trends for increased insoluble phospho-tau. d Displays representative Western blot images of monomeric tau at $55 \mathrm{kDa}$. Intensity of blots from all animals were averaged and converted to fold change for display. Data represented as mean \pm SEM, $n=9-12 . *$ denotes $p<0.05$ by two-tailed Student's t test

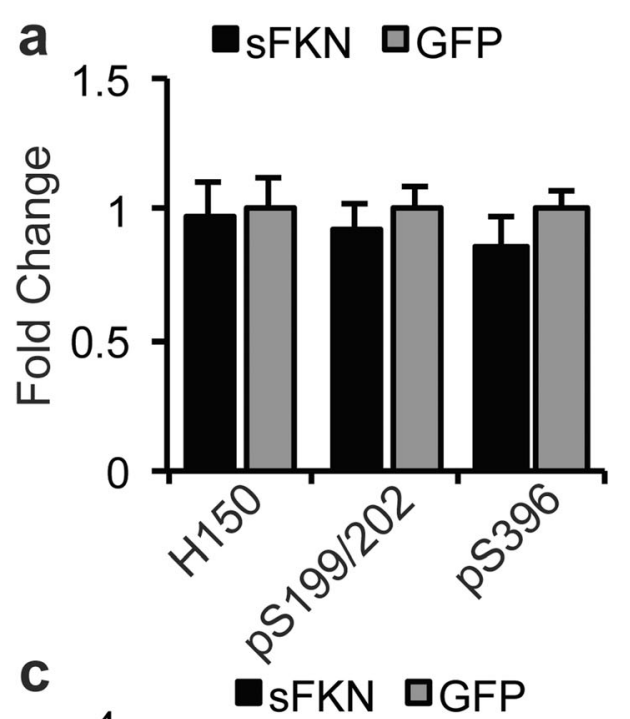

b

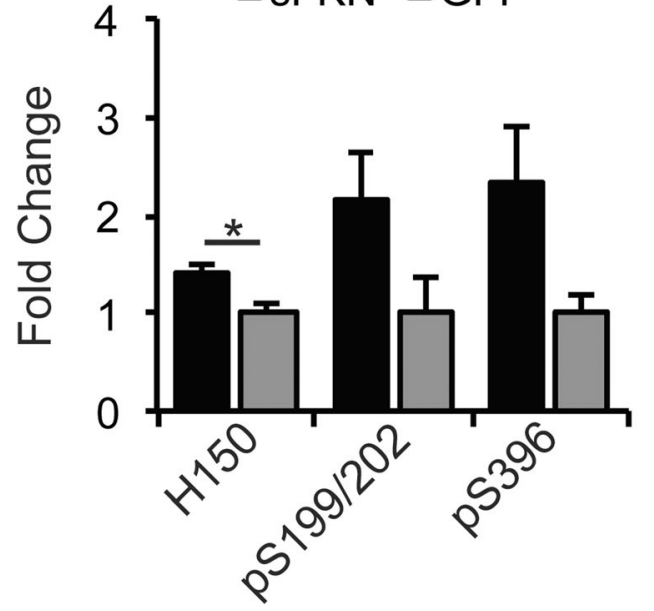

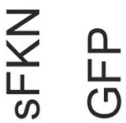

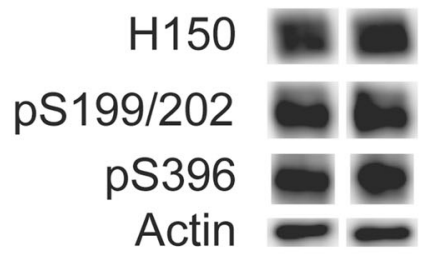

d
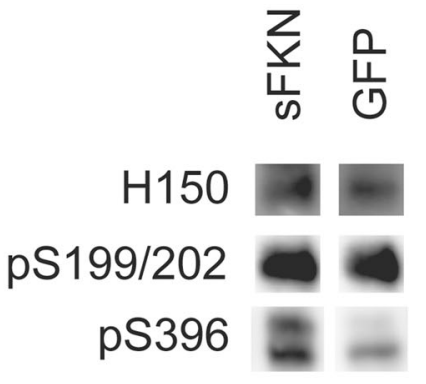

aqueduct, $3 \mathrm{rd}$ and 4 th ventricles. Using this method, we achieved an approximately 2 -fold increase of soluble FKN over endogenous levels.

Previous reports have implicated fractalkine signaling in neuropathic pain in the spinal cord (Clark and Malcangio 2012; Milligan et al. 2004). Since we secreted sFKN into the CSF, potentially increasing FKN signaling in the spinal cord, we were concerned this may have detrimental effects and thus examined the animals for thermal hyperalgesia on a hot plate. Animals over expressing sFKN had no change in latency to hind paw withdrawal as compared with GFP-injected controls (Fig. 3), indicating that either the levels of sFKN reaching the spinal cord are insufficient to cause hyperalgesia or the species (ADAM 10/17 product) of soluble FKN (aa 1-336) we over expressed does not participate in mediating neuropathic pain. The latter would be consistent with the data published by Clark and Malcangio (2012). They demonstrated that intrathecal administration of a peptide of the chemokine domain (amino acids $1-110$ only) results in mechanical hypersensitivity whereas an injection of the sFKN protein does not alter sensitivity (Clark and Malcangio 2012). Furthermore, induction of allodynia in spinal lesion models has been shown to be mediated, in part, by FKN and requires cathepsin S (Clark et al. 2007, 2009). These findings implicate the cathepsin S cleavage product of FKN, which migrates at a lower apparent molecular weight by SDS-PAGE than the ADAM 10/17 cleavage product used in the current study, in the induction of neuropathic pain (Fonovic et al. 2013).

Examining the behavioral phenotype of rTg4510s, we observed FKN expression above basal levels ameliorates several behavioral abnormalities. As reported previously, rTg4510s are known to be hyperactive and this hyperactivity may be due to pathological tau (Joly-Amado et al. 2016). Here, we observed a significant reduction in locomotor activity as measured in both the open field and Y-maze (Fig. 2). We also observed a significant improvement in novel mouse recognition, however, not novel object recognition (Fig. 2). This may be due to the greater motivation to interact with another mouse as opposed to an inanimate object (Brownlow et al. 2014). In the RAWM task, we observed that increased sFKN levels significantly improved hippocampal-dependent spatial learning and memory (Fig. 4). Animals over expressing sFKN made significantly fewer errors on Day 2 of the task than GFP-injected rTg4510s. However, we observed no 

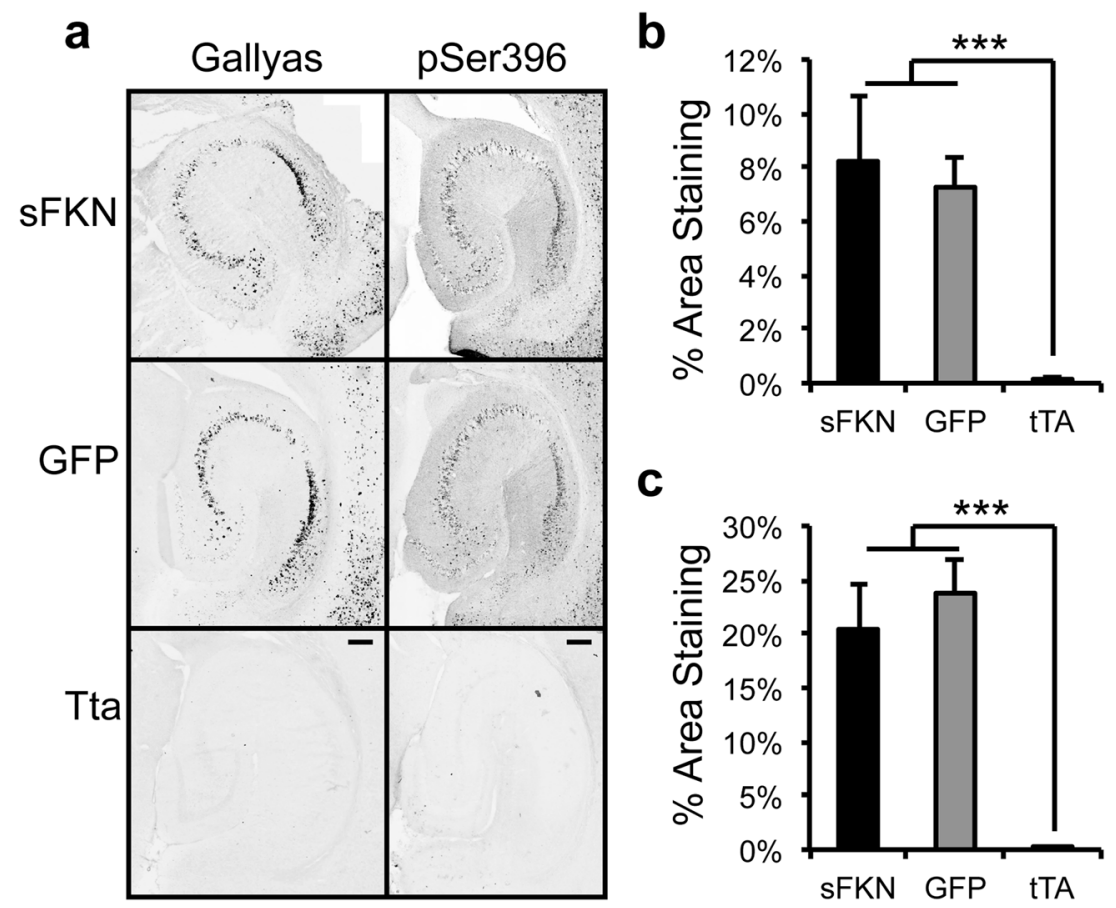

Fig. 6 sFKN over expression did not reduce pSer396 phospho-tau or Gallyas-positive tau tangles. a Representative images of hippocampi from mice treated with AAV-sFKN, AAV-GFP or control untreated tTA mice after staining by the Gallyas method for neurofibrillary tangles (left) or by immunostaining for pSer396 (right). Neurons expressing tau are visible in the CA subfield as dark reaction product. Scale bar $=200 \mu \mathrm{m}$. b Percentage area occupied by Gallyas reaction product was quantified on 8

improvement in the Reversal task, suggesting that this spatial learning improvement was partial. This may be due to the severe pathology that these animals already exhibited prior to start of sFKN treatment. This would suggest that earlier intervention, prior to significant neuropathology and neurodegeneration, may be a more beneficial therapeutic strategy.

We believe that the improvements we observed in behavior are due to alterations in the inflammatory milieu brought about by sFKN over expression. Previous studies have demonstrated that $\mathrm{Cx} 3 \mathrm{cr} 1-/-$ mice have deficits in cognition and neurogenesis that was reversed with IL-1 Receptor Antagonist (IL-1RA) administration (Bachstetter et al. 2011; Rogers et al. 2011). Microglial-specific cytotoxicity in an adoptive transfer model was also blocked by genetic ablation of IL-1 signaling (Cardona et al. 2006). Similarly, tau hyperphosphorylation induced by adoptive transfer of activated microglia from LPS-challenged hTau; $C x 3 c r 1-/-$ mice into naïve wild-type mice was blocked by administration of the IL-1R antagonist Kineret (Maphis et al. 2015). Antagonism of IL-1R has also been shown to improve cognitive deficits in the 3xTg model of AD (Kitazawa et al. 2011). Finally, a recent report showed that activated microglia can induce a neurotoxic phenotype in astrocytes, that these activated astrocytes are present in AD tissue, and blockage of the transformation of astrocytes into neurotoxic astrocytes can be neuroprotective (Liddelow et al. sections per mouse, averaged to yield a single value per mouse, then averaged over all mice per treatment condition. Although there was a genotype effect with rTg4510 mice displaying tangles and tTA mice lacking tangles, there was no effect of treatment with sFKN compared with GFP. c Similar quantitation of pSer396 phospho-tau staining as measured by IHC yielded equivalent conclusions. Data represented as mean \pm SEM, $n=9-12$. *** denotes $p<0.001$ by Fisher's LSD

2017). Given that FKN agonism reduces pro-inflammatory gene expression, FKN agonism may promote an environment more permissive to learning and memory (Lyons et al. 2009).

Besides cytokine secretion, microglia are also directly involved in synaptic homeostasis. Depletion of microglia caused cognitive deficits and removal of microglialderived brain derived neurotrophic factor recapitulated these effects, implicating microglial neurotrophic support in learning and memory (Parkhurst et al. 2013). Furthermore, microglia are involved in synaptic engulfment, both in disease and homeostasis (Hong et al. 2016; Schafer et al. 2012). Microglial dysfunction and senescence have been implicated in AD and clearance of senescent glial cells has recently been shown to improve recognition memory in the PS19 model of tauopathy (Bussian et al. 2018; Miller and Streit 2007). Increased FKN agonism may return microglia to a homeostatic state, facilitating learning.

Interestingly, we did not observe changes in microglial pan markers (CD45 and IBA-1), but this is consistent with what we have observed in previous studies in Parkinson's disease where we showed a neuroprotective effect of sFKN over expression but no concomitant reduction in MHC-II expression (Nash et al. 2015). A likely explanation is that we are altering the microglial state with the addition of sFKN rather than decreasing the level of activation, as these markers can be 


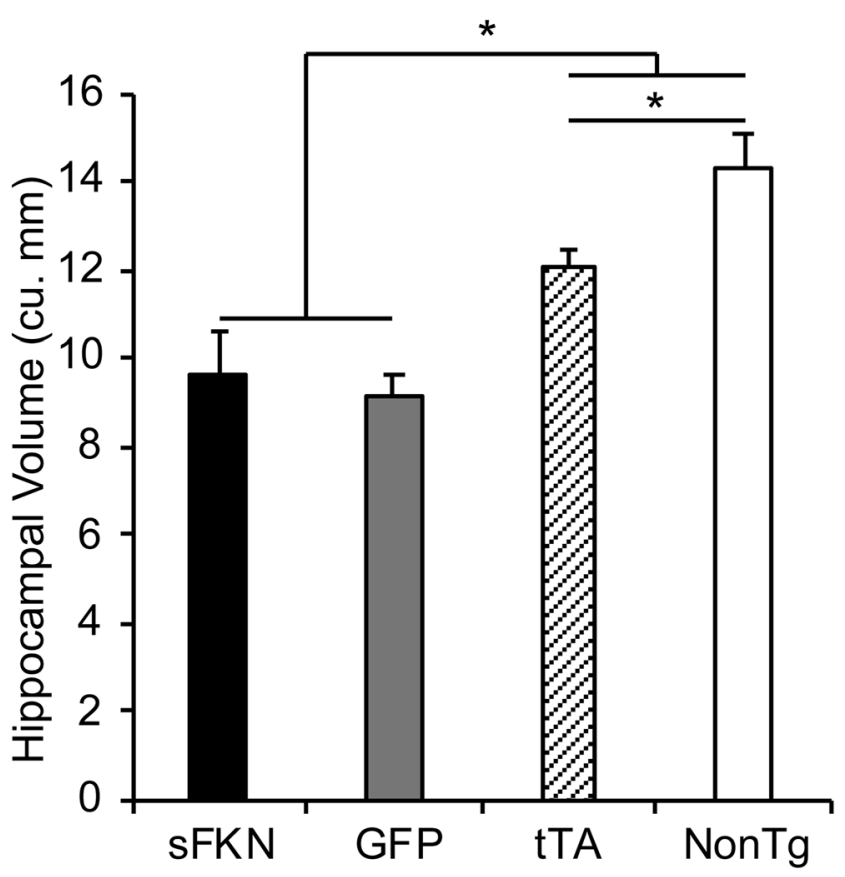

Fig. 7 rTg4510s have reduced hippocampal volume. Graph of hippocampal volume. Hippocampal area was quantified across 8 equally spaced sections spanning the hippocampus per mouse, which were averaged to generate one value per animal and finally averaged across all mice in one treatment group. $\mathrm{rTg} 4510$ s have reduced hippocampal volume compared to uninjected tTA and NonTg controls. Uninjected tTA mice also displayed reduced hippocampal volume compared to uninjected NonTg mice. Data represented as mean $\pm \mathrm{SEM}$, $n=9-12 . *$ denotes $p<0.05$ by Fisher's LSD increased in both proinflammatory and alternative activated states (Lee et al. 2013). We believe that the sFKN subtly altered microglial activation in a such a way that is more permissive to learning without altering expression of either CD45 or IBA-1. We would predict that this altered state would be less pro-inflammatory and possibly more neuroprotective.

To further investigate alterations in microglial activation, we examined a panel of immune-related genes by qPCR and observed a significant increase in Vegfa expression in animals over expressing sFKN. While vascular endothelial growth factor (VEGF) is most known for angiogenesis, it can also impact neurogenesis and promote neuron survival. VEGF has been shown to protect primary hippocampal neurons from excitotoxicity in vitro and promote neurogenesis in vivo (Jin et al. 2002; Matsuzaki et al. 2001). In neurodegenerative diseases, VEGF has been shown to be neuroprotective in Parkinson's disease, amyotrophic lateral sclerosis, and Alzheimer's disease models (Dodge et al. 2010; Religa et al. 2013; Tian et al. 2007). Neuroprotective effects are mediated both by direct anti-apoptotic signaling in neurons, neurogenesis, and through increased trophic support (Jin et al. 2001, 2002; Storkebaum and Carmeliet 2004; Sun et al. 2003). We hypothesize this increase in trophic support improved neuronal function, which may explain the improvement in cognitive performance observed in this study. Closer examination of the microglial profile with sFKN agonism is the focus of our current investigations.
Fig. 8 sFKN over expression did not reduce microglial activation. a Representative images of CD45 and IBA-1 immunoreactivity. Scale bar $=20 \mu \mathrm{m}$. b Percentage area staining for CD45. c

Percentage area staining for IBA1. Immunoreactivity was quantified across 8 sections per mouse, which were averaged to generate one value per animal and finally averaged across all mice in one treatment group. rTg4510s displayed more area staining of CD45 and IBA-1 than uninjected tTA and NonTg controls, but sFKN did not reduce this staining. Data represented as mean \pm SEM, $n=9-12$. ** denotes $p<0.01$, * denotes $p<0.05$ by Fisher's LSD

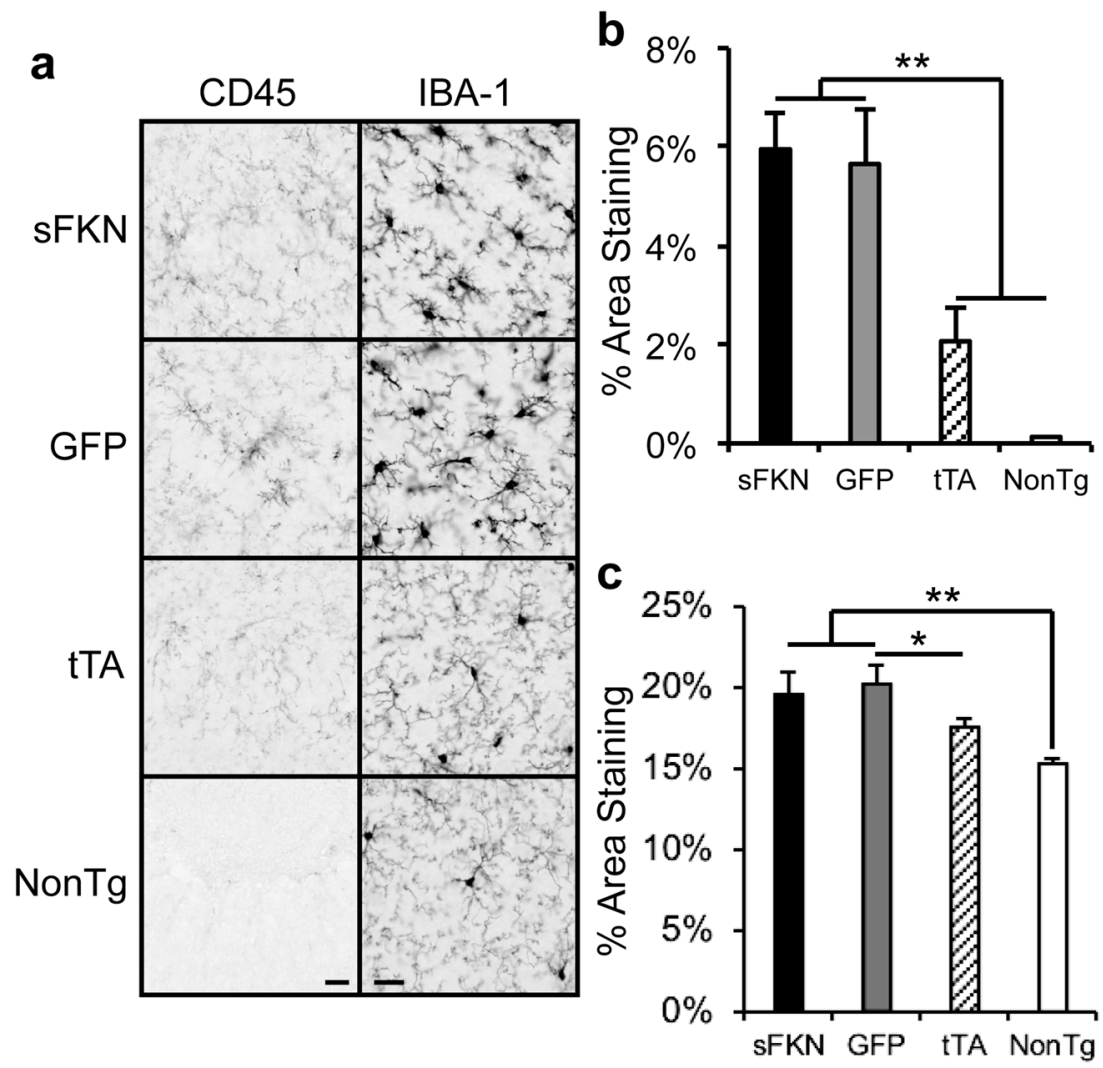




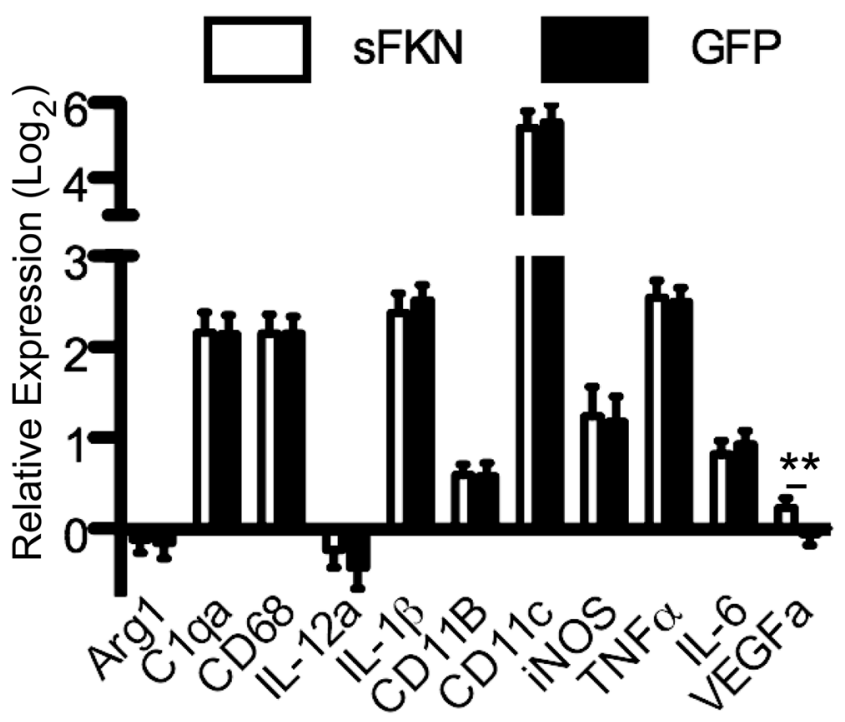

Fig. 9 sFKN over expression increased Vegfa expression. Graph of log base-2 expression relative to uninjected nontransgenic control mice. Data analyzed using $\Delta \Delta \mathrm{C}_{\mathrm{T}}$ method. Data represented as mean $\pm \mathrm{SEM}, n=4$ 7. ** denotes $p<0.01$ by two-tailed Student's t test

rTg4510 mice begin to show tau pathology as early as 34 months of age with behavioral deficits starting as early as 2.5 months (Dickey et al. 2009; Santacruz et al. 2005). By 6 months of age, rTg4510s have significant insoluble tau deposits and marked neuron loss and behavioral deficits. Furthermore, accumulation of insoluble tau species plateaus from 5.5 months of age onward, as does accumulation of a $64 \mathrm{kDa}$ soluble phospho-tau species (Dickey et al. 2009; Santacruz et al. 2005). Examining the tau pathology in the sFKN treated animals, we observed no significant change in soluble total tau or soluble phospho-tau species, but interestingly we did observe a significant small increase in insoluble total tau in animals over expressing sFKN. When we examined tau pathology by immunohistochemical means, we observed no increase in pSer396 phospho-tau and no increase in Gallyas-positive tau tangles. The inability of sFKN over expression to slow tau pathology here is possibly due to achievement of stable, plateau levels of pathology already present at the time of injection (Dickey et al. 2009; Santacruz et al. 2005; Spires et al. 2006). Alternatively, it may also require higher elevations of sFKN than we obtained here to reduce the accumulation of tau in these mice.

It is also important to note that our results are similar to those reported where the tau transgene expression was suppressed with doxycycline at 5.5 months of age (Ramsden et al. 2005; Santacruz et al. 2005). The mice on doxycycline improved in spatial learning tasks at 7 and 9.5 months compared to those without doxycycline, but the treated mice had no reductions in neurofibrillary tangles, PHF-1 positive neurons, or neuron number in the CA1 subfield (Santacruz et al. 2005). The recovery of memory in this mouse model, by doxycycline and now sFKN treatment, suggests that irreversible structural degeneration may not be responsible for initial memory deficits and that there is potential to recover some cognitive function in early stages of the disease. Indeed, this uncoupling of insoluble tau deposition from neuron loss and cognitive deficits is not unique to this model, as NFT formation does not correlate well with neuron loss in the human brain (Berger et al. 2007; Gomez-Isla et al. 1997; Spires-Jones et al. 2011). This could open the door for some medications to have profound improvements in quality of life for patients and delay the need and reduce the cost of extensive residential care. It has been estimated that a five-year delay in AD could lead to a $40 \%$ reduction in costs by 2050 (Zissimopoulos et al. 2014).

We have previously demonstrated that SFKN can be beneficial in a preventative approach in $\mathrm{rTg} 4510$ mice with administration at three months of age, prior to significant pathology. Here we shown that delivery of sFKN, using AAV4, can have a beneficial cognitive effect in $\mathrm{rTg} 4510$ mice with advanced pathology, at five months of age. In this study, we show the utility of delivering AAV4 to the lateral ventricles and over expressing a soluble immunomodulator into the CSF to achieve broad delivery of a therapeutic gene product to treat tauopathy. We have shown that this delivery method can meaningfully increase $\mathrm{sFKN}$ concentrations in the hippocampus as well as ameliorate behavioral deficits in the rTg4510 mouse model of tauopathy with advanced tau pathology. These data suggest that immunomodulation could have significant benefits in $\mathrm{AD}$ patients which already show tau pathology.

Funding This study was funded by Alzheimer's Association grant ZEN15-321311 and the UK Dementia Consortium.

\section{Compliance with Ethical Standards}

Conflicts of Interest The authors declare that they have no conflicts of interest.

Ethical Approval All procedures performed in studies involving animals were in accordance with the ethical standards of the institution at which studies were conducted.

Open Access This article is distributed under the terms of the Creative Commons Attribution 4.0 International License (http:// creativecommons.org/licenses/by/4.0/), which permits unrestricted use, distribution, and reproduction in any medium, provided you give appropriate credit to the original author(s) and the source, provide a link to the Creative Commons license, and indicate if changes were made.

Publisher's Note Springer Nature remains neutral with regard to jurisdictional claims in published maps and institutional affiliations.

\section{References}

Alamed J, Wilcock DM, Diamond DM, Gordon MN, Morgan D (2006) Two-day radial-arm water maze learning and memory task; robust 
resolution of amyloid-related memory deficits in transgenic mice. Nat Protoc 1:1671-1679. https://doi.org/10.1038/nprot.2006.275

Bachstetter AD, Morganti JM, Jernberg J, Schlunk A, Mitchell SH, Brewster KW, Hudson CE, Cole MJ, Harrison JK, Bickford PC, Gemma C (2011) Fractalkine and CX 3 CR1 regulate hippocampal neurogenesis in adult and aged rats. Neurobiol Aging 32:2030 2044. https://doi.org/10.1016/j.neurobiolaging.2009.11.022

Bazan JF, Bacon KB, Hardiman G, Wang W, Soo K, Rossi D, Greaves DR, Zlotnik A, Schall TJ (1997) A new class of membrane-bound chemokine with a CX3C motif. Nature 385:640-644. https://doi. org $/ 10.1038 / 385640 \mathrm{a} 0$

Berger Z, Roder H, Hanna A, Carlson A, Rangachari V, Yue M, Wszolek Z, Ashe K, Knight J, Dickson D, Andorfer C, Rosenberry TL, Lewis J, Hutton M, Janus C (2007) Accumulation of pathological tau species and memory loss in a conditional model of tauopathy. $\mathrm{J}$ Neurosci 27:3650-3662. https://doi.org/10.1523/JNEUROSCI. 0587-07.2007

Bhaskar K, Konerth M, Kokiko-Cochran ON, Cardona A, Ransohoff RM, Lamb BT (2010) Regulation of tau pathology by the microglial fractalkine receptor. Neuron 68:19-31. https://doi.org/10.1016/j. neuron.2010.08.023

Brownlow ML, Benner L, D'Agostino D, Gordon MN, Morgan D (2013) Ketogenic diet improves motor performance but not cognition in two mouse models of Alzheimer's pathology. PLoS One 8:e75713. https://doi.org/10.1371/journal.pone.0075713

Brownlow ML, Joly-Amado A, Azam S, Elza M, Selenica ML, Pappas C, Small B, Engelman R, Gordon MN, Morgan D (2014) Partial rescue of memory deficits induced by calorie restriction in a mouse model of tau deposition. Behav Brain Res 271:79-88. https://doi. org/10.1016/j.bbr.2014.06.001

Burger C, Nash KR (2016) Small-scale recombinant adeno-associated virus purification. Methods Mol Biol 1382:95-106. https://doi.org/ 10.1007/978-1-4939-3271-9_7

Bussian TJ, Aziz A, Meyer CF, Swenson BL, van Deursen JM, Baker DJ (2018) Clearance of senescent glial cells prevents tau-dependent pathology and cognitive decline. Nature 562:578-582. https://doi. org/10.1038/s41586-018-0543-y

Cardona AE, Pioro EP, Sasse ME, Kostenko V, Cardona SM, Dijkstra IM, Huang DR, Kidd G, Dombrowski S, Dutta RJ, Lee JC, Cook DN, Jung S, Lira SA, Littman DR, Ransohoff RM (2006) Control of microglial neurotoxicity by the fractalkine receptor. Nat Neurosci 9:917-924. https://doi.org/10.1038/nn1715

Carty N, Lee D, Dickey C, Ceballos-Diaz C, Jansen-West K, Golde TE, Gordon MN, Morgan D, Nash K (2010) Convection-enhanced delivery and systemic mannitol increase gene product distribution of AAV vectors 5,8 , and 9 and increase gene product in the adult mouse brain. J Neurosci Methods 194:144-153. https://doi.org/10. 1016/j.jneumeth.2010.10.010

Cho SH, Sun B, Zhou Y, Kauppinen TM, Halabisky B, Wes P, Ransohoff RM, Gan L (2011) CX3CR1 protein signaling modulates microglial activation and protects against plaque-independent cognitive deficits in a mouse model of Alzheimer disease. J Biol Chem 286:3271332722. https://doi.org/10.1074/jbc.M111.254268

Clark AK, Malcangio M (2012) Microglial signalling mechanisms: Cathepsin S and Fractalkine. Exp Neurol 234:283-292. https://doi. org/10.1016/j.expneurol.2011.09.012

Clark AK, Yip PK, Grist J, Gentry C, Staniland AA, Marchand F, Dehvari M, Wotherspoon G, Winter J, Ullah J, Bevan S, Malcangio M (2007) Inhibition of spinal microglial cathepsin S for the reversal of neuropathic pain. Proc Natl Acad Sci U S A 104:10655-10660. https://doi.org/10.1073/pnas.0610811104

Clark AK, Yip PK, Malcangio M (2009) The liberation of fractalkine in the dorsal horn requires microglial cathepsin S. J Neurosci 29:69456954. https://doi.org/10.1523/JNEUROSCI.0828-09.2009

Davidson BL, Stein CS, Heth JA, Martins I, Kotin RM, Derksen TA, Zabner J, Ghodsi A, Chiorini JA (2000a) Recombinant adeno- associated virus type 2, 4, and 5 vectors: transduction of variant cell types and regions in the mammalian central nervous system. Proc Natl Acad Sci U S A 97:3428-3432. https://doi.org/10.1073/pnas. 050581197

Davidson BL et al (2000b) Recombinant adeno-associated virus type 2, 4, and 5 vectors: transduction of variant cell types and regions in the mammalian central nervous system. Proc Natl Acad Sci USA 97: 3428-3432. https://doi.org/10.1073/pnas.050581197

Dickey C, Kraft C, Jinwal U, Koren J, Johnson A, Anderson L, Lebson L, Lee D, Dickson D, de Silva R, Binder LI, Morgan D, Lewis J (2009) Aging analysis reveals slowed tau turnover and enhanced stress response in a mouse model of tauopathy. Am J Pathol 174:228 238. https://doi.org/10.2353/ajpath.2009.080764

Dodge JC, Treleaven CM, Fidler JA, Hester M, Haidet A, Handy C, Rao M, Eagle A, Matthews JC, Taksir TV, Cheng SH, Shihabuddin LS, Kaspar BK (2010) AAV4-mediated expression of IGF-1 and VEGF within cellular components of the ventricular system improves survival outcome in familial ALS mice. Mol Ther 18:2075-2084. https://doi.org/10.1038/mt.2010.206

Fonovic UP, Jevnikar Z, Kos J (2013) Cathepsin S generates soluble CX3CL1 (fractalkine) in vascular smooth muscle cells. Biol Chem 394:1349-1352. https://doi.org/10.1515/hsz-2013-0189

Garton KJ, Gough PJ, Blobel CP, Murphy G, Greaves DR, Dempsey PJ, Raines EW (2001) Tumor necrosis factor-alpha-converting enzyme (ADAM17) mediates the cleavage and shedding of fractalkine (CX3CL1). J Biol Chem 276:37993-38001. https://doi.org/10. 1074/jbc.M106434200

Gomez-Isla T et al (1997) Neuronal loss correlates with but exceeds neurofibrillary tangles in Alzheimer's disease. Ann Neurol 41:1724. https://doi.org/10.1002/ana.410410106

Gordon MN, Holcomb LA, Jantzen PT, DiCarlo G, Wilcock D, Boyett KW, Connor K, Melachrino J, O'Callaghan JP, Morgan D (2002) Time course of the development of Alzheimer-like pathology in the doubly transgenic PS1+APP mouse. Exp Neurol 173:183-195. https://doi.org/10.1006/exnr.2001.7754

Harrison JK et al (1998) Role for neuronally derived fractalkine in mediating interactions between neurons and CX3CR1-expressing microglia. Proc Natl Acad Sci USA 95:10896-10901. https://doi.org/ 10.1073/pnas.95.18.10896

Herber DL, Mercer M, Roth LM, Symmonds K, Maloney J, Wilson N, Freeman MJ, Morgan D, Gordon MN (2007) Microglial activation is required for Abeta clearance after intracranial injection of lipopolysaccharide in APP transgenic mice. J NeuroImmune Pharmacol 2:222-231. https://doi.org/10.1007/s11481-007-9069-z

Hong S, Beja-Glasser VF, Nfonoyim BM, Frouin A, Li S, Ramakrishnan S, Merry KM, Shi Q, Rosenthal A, Barres BA, Lemere CA, Selkoe DJ, Stevens B (2016) Complement and microglia mediate early synapse loss in Alzheimer mouse models. Science 352:712-716. https://doi.org/10.1126/science.aad8373

Hundhausen C, Misztela D, Berkhout TA, Broadway N, Saftig P, Reiss K, Hartmann D, Fahrenholz F, Postina R, Matthews V, Kallen KJ, Rose-John S, Ludwig A (2003) The disintegrin-like metalloproteinase ADAM10 is involved in constitutive cleavage of CX3CL1 (fractalkine) and regulates CX3CL1-mediated cell-cell adhesion. Blood 102:1186-1195. https://doi.org/10. 1182/blood-2002-12-3775

Imai T, Hieshima K, Haskell C, Baba M, Nagira M, Nishimura M, Kakizaki M, Takagi S, Nomiyama H, Schall TJ, Yoshie O (1997) Identification and molecular characterization of fractalkine receptor CX3CR1, which mediates both leukocyte migration and adhesion. Cell 91:521-530

Jin K, Mao XO, Batteur SP, McEachron E, Leahy A, Greenberg DA (2001) Caspase- 3 and the regulation of hypoxic neuronal death by vascular endothelial growth factor. Neuroscience 108:351-358

Jin K, Zhu Y, Sun Y, Mao XO, Xie L, Greenberg DA (2002) Vascular endothelial growth factor (VEGF) stimulates neurogenesis in vitro 
and in vivo. Proc Natl Acad Sci U S A 99:11946-11950. https://oi. org/10.1073/pnas.182296499

Joly-Amado A, Serraneau KS, Brownlow M, Marin de Evsikova C, Speakman JR, Gordon MN, Morgan D (2016) Metabolic changes over the course of aging in a mouse model of tau deposition. Neurobiol Aging 44:62-73. https://doi.org/10.1016/j. neurobiolaging.2016.04.013

Jones BA, Riegsecker S, Rahman A, Beamer M, Aboualaiwi W, Khuder SA, Ahmed S (2013) Role of ADAM-17, p38 MAPK, cathepsins, and the proteasome pathway in the synthesis and shedding of fractalkine/CX(3) CL1 in rheumatoid arthritis. Arthritis Rheum 65: 2814-2825. https://doi.org/10.1002/art.38095

Kim KW, Vallon-Eberhard A, Zigmond E, Farache J, Shezen E, Shakhar G, Ludwig A, Lira SA, Jung S (2011) In vivo structure/function and expression analysis of the CX3C chemokine fractalkine. Blood 118: e156-e167. https://doi.org/10.1182/blood-2011-04-348946

Kitazawa M, Cheng D, Tsukamoto MR, Koike MA, Wes PD, Vasilevko V, Cribbs DH, LaFerla FM (2011) Blocking IL-1 signaling rescues cognition, attenuates tau pathology, and restores neuronal beta-catenin pathway function in an Alzheimer's disease model. J Immunol 187:6539-6549. https://doi.org/10.4049/ jimmunol.1100620

Lee DC, Rizer J, Selenica MLB, Reid P, Kraft C, Johnson A, Blair L, Gordon MN, Dickey CA, Morgan D (2010a) LPS- induced inflammation exacerbates phospho-tau pathology in rTg4510 mice. J Neuroinflammation 7:56. https://doi.org/10.1186/1742-2094-7-56

Lee S, Varvel NH, Konerth ME, Xu G, Cardona AE, Ransohoff RM, Lamb BT (2010b) CX3CR1 deficiency alters microglial activation and reduces beta-amyloid deposition in two Alzheimer's disease mouse models. Am J Pathol 177:2549-2562. https://doi.org/10. 2353/ajpath.2010.100265

Lee DC, Ruiz CR, Lebson L, Selenica MLB, Rizer J, Hunt JB Jr, Rojiani R, Reid P, Kammath S, Nash K, Dickey CA, Gordon M, Morgan D (2013) Aging enhances classical activation but mitigates alternative activation in the central nervous system. Neurobiol Aging 34:1610 1620. https://doi.org/10.1016/j.neurobiolaging.2012.12.014

Liddelow SA, Guttenplan KA, Clarke LE, Bennett FC, Bohlen CJ, Schirmer L, Bennett ML, Münch AE, Chung WS, Peterson TC, Wilton DK, Frouin A, Napier BA, Panicker N, Kumar M, Buckwalter MS, Rowitch DH, Dawson VL, Dawson TM, Stevens B, Barres BA (2017) Neurotoxic reactive astrocytes are induced by activated microglia. Nature 541:481-487. https://doi.org/10.1038/nature21029

Liu L, Duff K (2008) A technique for serial collection of cerebrospinal fluid from the cisterna magna in mouse. J Vis Exp 21. https://doi. org/10.3791/960

Liu G, Martins I, Wemmie JA, Chiorini JA, Davidson BL (2005) Functional correction of CNS phenotypes in a lysosomal storage disease model using adeno-associated virus type 4 vectors. J Neurosci 25:9321-9327. https://doi.org/10.1523/JNEUROSCI. 2936-05.2005

Lyons A, Lynch AM, Downer EJ, Hanley R, O'Sullivan JB, Smith A, Lynch MA (2009) Fractalkine-induced activation of the phosphatidylinositol-3 kinase pathway attentuates microglial activation in vivo and in vitro. J Neurochem 110:1547-1556. https://doi. org/10.1111/j.1471-4159.2009.06253.x

Maphis N, Xu G, Kokiko-Cochran ON, Jiang S, Cardona A, Ransohoff RM, Lamb BT, Bhaskar K (2015) Reactive microglia drive tau pathology and contribute to the spreading of pathological tau in the brain. Brain 138:1738-1755. https://doi.org/ 10.1093/brain/awv081

Matsuzaki $\mathrm{H}$ et al (2001) Vascular endothelial growth factor rescues hippocampal neurons from glutamate-induced toxicity: signal transduction cascades. FASEB J 15:1218-1220

Meijer DH, Maguire CA, Leroy SG, Sena-Esteves M (2009) Controlling brain tumor growth by intraventricular administration of an AAV vector encoding IFN-beta. Cancer Gene Ther 16:664-671. https:// doi.org/10.1038/cgt.2009.8

Miller KR, Streit WJ (2007) The effects of aging, injury and disease on microglial function: a case for cellular senescence. Neuron Glia Biol 3:245-253. https://doi.org/10.1017/S1740925X08000136

Milligan ED, Zapata V, Chacur M, Schoeniger D, Biedenkapp J, O'Connor KA, Verge GM, Chapman G, Green P, Foster AC, Naeve GS, Maier SF, Watkins LR (2004) Evidence that exogenous and endogenous fractalkine can induce spinal nociceptive facilitation in rats. Eur J Neurosci 20:2294-2302. https://doi.org/10.1111/j. 1460-9568.2004.03709.x

Morganti JM, Nash KR, Grimmig BA, Ranjit S, Small B, Bickford PC, Gemma C (2012) The soluble isoform of CX3CL1 is necessary for neuroprotection in a mouse model of Parkinson's disease. J Neurosci 32:14592-14601. https://doi.org/10.1523/ JNEUROSCI.0539-12.2012

Nash KR, Gordon MN (2016) Convection enhanced delivery of recombinant adeno-associated virus into the mouse brain. Methods Mol Biol 1382:285-295. https://doi.org/10.1007/978-1-4939-3271-9_21

Nash KR, Lee DC, Hunt JB Jr, Morganti JM, Selenica ML, Moran P, Reid P, Brownlow M, Guang-Yu Yang C, Savalia M, Gemma C, Bickford PC, Gordon MN, Morgan D (2013) Fractalkine overexpression suppresses tau pathology in a mouse model of tauopathy. Neurobiol Aging 34:1540-1548. https://doi.org/10.1016/j.neurobiolaging. 2012.12.011

Nash KR, Moran P, Finneran DJ, Hudson C, Robinson J, Morgan D, Bickford PC (2015) Fractalkine over expression suppresses alphasynuclein-mediated neurodegeneration. Mol Ther 23:17-23. https:// doi.org/10.1038/mt.2014.175

Pabon MM, Bachstetter AD, Hudson CE, Gemma C, Bickford PC (2011) CX3CL1 reduces neurotoxicity and microglial activation in a rat model of Parkinson's disease. J Neuroinflammation 8:9. https://doi. org/10.1186/1742-2094-8-9

Pan Y, Lloyd C, Zhou H, Dolich S, Deeds J, Gonzalo JA, Vath J, Gosselin M, Ma J, Dussault B, Woolf E, Alperin G, Culpepper J, GutierrezRamos JC, Gearing D (1997) Neurotactin, a membrane-anchored chemokine upregulated in brain inflammation. Nature 387:611617. https://doi.org/10.1038/42491

Parkhurst CN, Yang G, Ninan I, Savas JN, Yates JR III, Lafaille JJ, Hempstead BL, Littman DR, Gan WB (2013) Microglia promote learning-dependent synapse formation through brain-derived neurotrophic factor. Cell 155:1596-1609. https://doi.org/10.1016/j.cell. 2013.11.030

Ramsden M, Kotilinek L, Forster C, Paulson J, McGowan E, SantaCruz K, Guimaraes A, Yue M, Lewis J, Carlson G, Hutton M, Ashe KH (2005) Age-dependent neurofibrillary tangle formation, neuron loss, and memory impairment in a mouse model of human tauopathy (P301L). J Neurosci 25:10637-10647. https://doi.org/10.1523/ JNEUROSCI.3279-05.2005

Religa P, Cao R, Religa D, Xue Y, Bogdanovic N, Westaway D, Marti HH, Winblad B, Cao Y (2013) VEGF significantly restores impaired memory behavior in Alzheimer's mice by improvement of vascular survival. Sci Rep 3:2053. https://doi.org/10.1038/ srep02053

Rogers JT, Morganti JM, Bachstetter AD, Hudson CE, Peters MM, Grimmig BA, Weeber EJ, Bickford PC, Gemma C (2011) CX3CR1 deficiency leads to impairment of hippocampal cognitive function and synaptic plasticity. J Neurosci 31:16241-16250. https://doi.org/10.1523/JNEUROSCI.3667-11.2011

Santacruz K, Lewis J, Spires T, Paulson J, Kotilinek L, Ingelsson M, Guimaraes A, DeTure M, Ramsden M, McGowan E, Forster C, Yue M, Orne J, Janus C, Mariash A, Kuskowski M, Hyman B, Hutton M, Ashe KH (2005) Tau suppression in a neurodegenerative mouse model improves memory function. Science 309:476-481. https://doi.org/10.1126/science.1113694 
Schafer DP, Lehrman EK, Kautzman AG, Koyama R, Mardinly AR, Yamasaki R, Ransohoff RM, Greenberg ME, Barres BA, Stevens B (2012) Microglia sculpt postnatal neural circuits in an activity and complement-dependent manner. Neuron 74:691-705. https://doi. org/10.1016/j.neuron.2012.03.026

Schmittgen TD, Livak KJ (2008) Analyzing real-time PCR data by the comparative CT method. Nat Protoc 3:1101-1108

Spires TL, Orne JD, SantaCruz K, Pitstick R, Carlson GA, Ashe KH, Hyman BT (2006) Region-specific dissociation of neuronal loss and neurofibrillary pathology in a mouse model of tauopathy. Am J Pathol 168:1598-1607. https://doi.org/10.2353/ajpath.2006.050840

Spires-Jones TL, Kopeikina KJ, Koffie RM, de Calignon A, Hyman BT (2011) Are tangles as toxic as they look? J Mol Neurosci 45:438444. https://doi.org/10.1007/s12031-011-9566-7

Storkebaum E, Carmeliet P (2004) VEGF: a critical player in neurodegeneration. J Clin Investig 113:14-18. https://doi.org/10.1172/jci20682

Sun Y, Jin K, Xie L, Childs J, Mao XO, Logvinova A, Greenberg DA (2003) VEGF-induced neuroprotection, neurogenesis, and angiogenesis after focal cerebral ischemia. J Clin Investig 111:18431851. https://doi.org/10.1172/jci200317977
Tenenbaum L, Chtarto A, Lehtonen E, Velu T, Brotchi J, Levivier M (2004) Recombinant AAV-mediated gene delivery to the central nervous system. J Gene Med 6(Suppl 1):S212-S222. https://doi. org/10.1002/jgm.506

Tian YY, Tang CJ, Wang JN, Feng Y, Chen XW, Wang L, Qiao X, Sun SG (2007) Favorable effects of VEGF gene transfer on a rat model of Parkinson disease using adeno-associated viral vectors. Neurosci Lett 421:239-244. https://doi.org/10.1016/j.neulet.2007.05.033

Watson G, Bastacky J, Belichenko P, Buddhikot M, Jungles S, Vellard M, Mobley WC, Kakkis E (2006) Intrathecal administration of AAV vectors for the treatment of lysosomal storage in the brains of MPS I mice. Gene Ther 13:917-925. https:// doi.org/10.1038/sj.gt.3302735

Woolfe G, Macdonald AD (1944) The evaluation of the analgesic action of pethidine hydrochloride (Demerol). J Pharmacol Exp Ther 80: 300-307

Zissimopoulos J, Crimmins E, St Clair P (2014) The value of delaying Alzheimer's disease onset. Forum Health Econ Policy 18:25-39. https://doi.org/10.1515/fhep-2014-0013 